\title{
EXIT $360^{\circ}$-EXecutive-Functions Innovative Tool $360^{\circ}-\mathrm{A}$ Simple and Effective Way to Study Executive Functions in Parkinson's Disease by Using $360^{\circ}$ Videos
}

\author{
Francesca Borgnis ${ }^{1,2}{ }^{1}$, Francesca Baglio ${ }^{1}$, Elisa Pedroli ${ }^{3,4}$, Federica Rossetto ${ }^{1}$, Mario Meloni ${ }^{1}$, \\ Giuseppe Riva ${ }^{2,3(1)}$ and Pietro Cipresso ${ }^{3,5, *}$
}

1 IRCCS Fondazione Don Carlo Gnocchi ONLUS, 20148 Milan, Italy; fborgnis@dongnocchi.it (F.B.); fbaglio@dongnocchi.it (F.B.); frossetto@dongnocchi.it (F.R.); mmeloni@dongnocchi.it (M.M.)

2 Department of Psychology, Università Cattolica del Sacro Cuore, 20123 Milan, Italy; giuseppe.riva@unicatt.it

3 Applied Technology for Neuro-Psychology Laboratory, Istituto Auxologico Italiano, Istituto di Ricovero e Cura a Carattere Scientifico, 20149 Milan, Italy; e.pedroli@auxologico.it

4 Faculty of Psychology, eCampus University, 22060 Novedrate, Italy

5 Department of Psychology, Università degli Studi di Torino, 10124 Turin, Italy

* Correspondence: p.cipresso@auxologico.it

Citation: Borgnis, F.; Baglio, F.; Pedroli, E.; Rossetto, F.; Meloni, M.; Riva, G.; Cipresso, P. EXIT $360^{\circ}$-EXecutive-Functions Innovative Tool $360^{\circ}-\mathrm{A}$ Simple and Effective Way to Study Executive Functions in Parkinson's Disease by Using $360^{\circ}$ Videos. Appl. Sci. 2021, 11 , 6791. https://doi.org/10.3390/ app11156791

Academic Editors: Enrico Vezzetti and Anton Civit

Received: 7 June 2021

Accepted: 21 July 2021

Published: 23 July 2021

Publisher's Note: MDPI stays neutral with regard to jurisdictional claims in published maps and institutional affiliations.

Copyright: (c) 2021 by the authors. Licensee MDPI, Basel, Switzerland. This article is an open access article distributed under the terms and conditions of the Creative Commons Attribution (CC BY) license (https:/ / creativecommons.org/licenses/by/ $4.0 /)$.
Featured Application: The validation of EXIT $360^{\circ}$ as an innovative tool for an ecologically valid assessment of executive functioning in Parkinson's disease will radically transform the assessment experience. The clinician will obtain faster (15 $\mathrm{min})$, multicomponent, and multidomain evaluations of executive functioning. Moreover, the patients will be involved in a short task (vs. a long and complicated assessment) that can be experienced as a "game for health", increasing engagement and lowering the level of emotional charge typical of neuropsychological evaluation. Finally, EXIT $360^{\circ}$ is easily transportable, so the assessment can also be performed in the patient's room or house, overcoming logistical challenges related to bringing a patient into the clinic.

Abstract: Executive dysfunction represents a common non-motor symptom in Parkinson's disease (PD), with a substantial negative impact on daily functioning and quality of life. Assessing executive functions (EFs) with ecological tools is therefore essential. The ecological limitations of traditional neuropsychological tests have led to increased use of virtual reality and $360^{\circ}$ environment-based tools for the assessment of EFs in real life. The study aims to evaluate the efficacy and usability of the EXecutive-Functions Innovative Tool $360^{\circ}$ (EXIT $360^{\circ}$ ), a $360^{\circ}$-based tool for the evaluation of EFs in PD. Twenty-five individuals with PD and 25 healthy controls (HC) will be assessed with a conventional neuropsychological battery and EXIT $360^{\circ}$ delivered via a head-mounted display. EXIT $360^{\circ}$ will show a domestic scenario and seven different subtasks of increasing complexity, and will collect verbal responses, reaction times, and physiological data. We expect that EXIT $360^{\circ}$ will be judged usable, engaging, and challenging. Moreover, we expect to find a highly convergent (conventional test and EXIT $360^{\circ}$ ) and diagnostic validity (individuals with PD vs. HC). The validation of EXIT $360^{\circ}$ will allow for the adoption of a fast, ecological, and useful instrument for PD screening, likely transforming the assessment for the clinic and the patient.

Keywords: executive functions; $360^{\circ}$ environments; assessment; Parkinson's disease; virtual reality; EEG; eye tracker

\section{Introduction}

Parkinson's disease (PD) is a progressive neurodegenerative disorder primarily considered as a movement disorder due to an extrapyramidal syndrome. However, in addition to the well-documented motor symptoms (e.g., bradykinesia, resting tremor, rigidity, and postural instability), people with PD frequently develop a wide range of non-motor symp- 
toms (NMS) from the early stages of the disease course, even before the onset of motor symptoms in the prodromal state [1-3].

Cognitive dysfunction represents one of the major clinical NMS of PD. People with PD can exhibit a rapid decline in several cognitive domains, especially in executive, attentional, and visuospatial [1]. However, the profile and the severity of the neuropsychological deficits vary considerably, depending on factors including the timing of the onset and the rate of progression [1,3]. Executive dysfunction (ED) represents the best-defined cognitive impairment in early-stage non-demented PD [4]. ED is mainly characterized by deficits in attention, planning, set shifting, dual task performance, inhibitory control, working memory, and decision making, even compromising social-cognition skills [5]. As a result, patients experience difficulty in many essential goal-directed everyday activities, with critical adverse implications for daily functioning and quality of life [6-8]. Therefore, identifying early strategies for the evaluation and rehabilitation of executive functions (EFs) is crucial to achieving optimal multilayer PD management.

\subsection{Executive Function Assessment}

EFs are traditionally evaluated with standard paper-and-pencil neuropsychological tests, such as the Modified Wisconsin Card Sorting Test [9] or the Trail Making Test [10], which allow standardized procedures and goals that make them valid and reliable. However, these tests have been shown to be unable to predict the complexity of executive functioning in real-life settings reliably [11-16] and seem inadequate in terms of sensitivity and specificity $[16,17]$. Thus, a more ecological evaluation of EFs is essential to evaluate the specific cognitive profile of individuals $[12,14,18]$ and how executive deficits affect daily functioning [14]. In an attempt to refine EF assessment, Burgess and colleagues proposed the development of neuropsychological assessments based on models derived from directly observable everyday behaviours. This "function-led" approach diverges from the emphasis on abstract cognitive "constructs" without regard for their ability to predict the complexity of "functional" behaviours found in real-life situations. Hence, there has been a need for new neuropsychological instruments that measure different components of executive functioning within real-life scenarios [18] such as the Multiple Errands Test (MET) [11] and the Executive Function Performance Test. For example, the MET evaluated patients while carrying out different daily tasks (e.g., shopping tasks) in a real supermarket, following specific rules within a specified time frame. The assessment in real-life settings provided a more accurate estimate of the patient's deficits than laboratory conditions [19]. However, it revealed further limitations, such as long times, high economic costs, difficulty of organization, lack of safety, poor controllability of experimental condition, or applicability to individuals with motor deficits [20]. For example, MET is conducted in real time in a real-life setting, limiting the use for patients who are not independent, and requiring high physician costs and time demands. Therefore, the ecological limitations of traditional neuropsychological tests and many difficulties in administering tests in real-life scenarios have led to the increasing use of technological tools and virtual reality (VR) for the assessment of EFs in real life.

\subsection{New Challenges in the Evaluation of Executive Functions}

The use of interactive technologies (e.g., virtual reality, mobile devices and sensors, serious games, and $360^{\circ}$ video) is quickly becoming a promising instrument in simulating a real environment, with high use in the healthcare sector, including neuropsychological assessment, rehabilitation [21], educational training [22,23], and surgery [24].

\subsubsection{Virtual Reality}

VR allows for the development of realistic spatial and temporal scenarios, situations, objects, and stimuli that reproduce conditions of everyday life, allowing an ecologically valid evaluation of EFs [25-28], as well as reliability and psychometric validity [29-31]. In other words, VR appears to be an appropriate tool for the assessment of EFs because 
it provides the chance to perform many everyday tasks in ecologically valid, secure, and controlled environments [26]. Thus, clinicians can directly observe their patients in an everyday setting (e.g., supermarkets, kitchens, or work office), while performing several executive tasks [32,33]. Moreover, the use of virtual environments in neuropsychological assessments guarantees better control of the perceptual environment, a more precise presentation of the stimulus, greater applicability, user-friendly interfaces, and the acquisition of data and analysis of performance in real time [27,28,31,34-37]. Several authors studied ED in PD through VR-based instruments that required performance of real-life tasks (e.g., a shopping task) in virtual environments that reproduced a real supermarket [13,38-41]. Among the EFs, planning represents an essential component of cognitive PD alteration. From the early stages of PD, planning deficits have been found and probably reflect frontostriatal circuit degeneration [42]. Klinger and colleagues developed a virtual supermarket to evaluate visuospatial and temporal aspects of planning using a 3D environment $[13,38]$. In this VR-based tool, clinicians evaluated the strategic choices and planning abilities of individuals with PD in buying a specific number of products. Data showed the absence of a significant difference between the PD group and the control group for the number of correct actions. On the contrary, the increased distance and duration and the inefficient trajectory observed in the PD group suggested a gradual decrease in planning processes in PD (slowness of information processing) and inefficient use of contextual elements. In other words, these results underlined the spatial and temporal aspects of planning deficits in PD. Moreover, the inefficient trajectory could also suggest a dysfunction in the switching mechanism necessary to process, in parallel, large amounts of information. Interestingly, VR allowed for the description of alterations in planning by testing "pure" mental sequences without the interference of possible motor disability.

In later years, several authors used the virtual version of the Multiple Errand Test (VMET) to evaluate executive disorders in PD patients ecologically. The VMET allows for the assessment of patients' abilities in formulating and checking a list of goals to effectively respond to environmental requests to achieve a series of tasks (e.g., buy a specific product, or ask the examiner information about a product to be purchased). In a preliminary study, Raspelli and colleagues showed the presence of many deficits in planning, which is the strategy that allows the correct execution of the task in problem-solving and set-shifting [43]. Specifically, individuals with PD use few strategies, and show more perseveration and difficulties in set-shifting and sustained attention. The following study conducted by Albani and colleagues also showed impairments in decision making in individuals with PD [44]. Patients showed strategies full of errors, suggesting impulsive decision making. These data can support the hypothesis that behavioural disturbance (in some individuals with PD) might precede cognitive dysfunctions in PD. Similar findings were found by Cipresso and colleagues that compared PD with normal cognition (PD-NC) and a control group [40]. Patients made more errors in the tasks of the VMET and demonstrated reduced use of effective strategies to complete the tasks, like careful planning before starting a subtask or using the map for navigating the virtual supermarket. These executive deficits may reflect impairments in cognitive flexibility, in which a person's conceptualization selectively changes to respond to external/internal stimulation. In the same study, it was shown that assessment in real-life contexts provides a more accurate estimate of the patient's impairment, revealing difficulties hidden by traditional measures. In fact, VMET appears more sensitive in the early detection of executive deficits, because these two groups did not differ in the standard assessment of EFs (Mini-Mental State Examination, Clock Drawing Test, and Tower of London). So, a more ecologically valid evaluation of EFs leads to better detection of subtle executive deficits, above all in the early stage of PD. An increasing number of longitudinal studies suggest early executive dysfunction is predictive of subsequent development of PD dementia [45,46]. Thus, the early identification of executive impairments could help identify those individuals with PD at risk of developing dementia and provide the opportunity for early neurorehabilitation interventions [40,41]. 
In recent years, some authors used a new technology for presenting neuropsychological stimuli, exploiting the potential of $360^{\circ}$ environments (photographs or immersive videos) provided via smartphone [47]. The $360^{\circ}$ technology can be included in the "virtuality continuum" of Milgram [48], in which stimuli are presented in a space between real and virtual, or "mixed reality", in which the extremes may coexist, producing new experiences. Advances in $360^{\circ}$ technologies allow participants to be immersed in a real situation that they experience from a first-person perspective. Specifically, the enhanced realism offered by $360^{\circ}$ video has great potential to lead to highly immersive, interactive, and engaging forms of experience [49]. Moreover, $360^{\circ}$ environments allow for sequential focusing upon several elements and portions of the environment at different times, and sequential planning of a visual search. Today, $360^{\circ}$ video appears to be a promising interactive virtual technology for creating virtual-reality-immersive applications at low cost [49]. The implementation of neuropsychological tests in $360^{\circ}$ environments is an actual challenge; in this direction, Serino and collaborators have recently developed a $360^{\circ}$ version of a validated paper-and-pencil test for the detection of executive deficits known as the Picture Interpretation Test (PIT) [50]. Serino and colleagues successfully tested the efficacy of PIT $360^{\circ}$ as a highly sensitive ecological tool for detecting executive deficits from the early stages of PD [47]. First, results showed a correlation between indices of PIT $360^{\circ}$ and two executive tests: the Trail Making Test and the phonemic fluency task. However, unlike traditional neuropsychological tests, PIT $360^{\circ}$ can distinguish the pathological group from controls both in terms of the time taken to arrive at the correct answer and in the number of elements of the scene named. Compared with healthy controls, individuals with PD gave significantly more detailed descriptions of the scene, had delayed time to provide a correct interpretation of the scene proposed, and appeared more prone to distractor interference. Thus, PD showed more difficulties in focusing on the most crucial components for a correct interpretation of the scene. These results were in line with Luria's view, suggesting that this test can capture deficits in active visual perception [51]. Interestingly, Luria found that disturbances in active visual perception were reflected by a corresponding disorganized movement of the scanning gaze. From this point of view, it would be interesting to investigate patients' eye movements during the interpretation of the proposed scene, integrating this technology with other portable devices, such as an eye tracker.

\subsubsection{Nonverbal Physiological Indices}

Over the years, executive functioning has been further explored by the identification new nonverbal physiological indices obtained with different devices, such as the eye tracker (ET) and electroencephalogram (EEG).

ETs allow for online tracking and recording of subjects' eye movements (e.g., saccadic and antisaccadic movements, and fixations). Physiological indices obtained with ETs (e.g., pupil dilation, eye movements, fixation, and gaze direction) are generally considered reliable indicators of executive dysfunction (e.g., inhibitory control) [37]. For example, Mirsky and colleagues demonstrated that antisaccadic movements are a sensitive marker of ED and frontal-lobe structure in cognitively and functionally healthy older adults [52]. Recently, Ouerfelli-Ethier and co-workers demonstrated the suitability of the antisaccades test (AST) as a cognitive marker of EFs in aging and PD populations [53]. AST performance was a good predictor of decision-making and visual-memory abilities for both older adults and PD patients, while it predicted visual search performance to a larger extent in $\mathrm{PD}$ patients. The advantages of ET and VR $/ 360^{\circ}$ environments (e.g., natural stimuli, natural movement, controlled environment, and controlled data collection) make it possible to answer many research questions in a radically innovative way. It allows for calculating the subject's gaze in the 3D virtual environment and observing where the subject is looking during the session. Moreover, ET allows for the definition of regions of interest in 3D space and fixation time of each area [54].

EEG, on the other hand, can be used to analyse, monitor, and record electrical activity and any functional anomalies in the prefrontal cortex and associated cortico-subcortical 
circuits, responsible for EFs [55,56]. "Dysexecutive syndrome" is common in neurological patients due to damage to the frontal lobe, such as following head trauma or related to specific conditions such as PD [57]. Slower oscillations within the theta frequency band in the frontal cortex, generally observed between 4 and $8 \mathrm{~Hz}$, are associated with the involvement of the neural resources involved in executive tasks. EEG can be used to estimate the complexity of executive dysfunction in several clinical populations (e.g., [58,59]). For example, a study conducted by Teramoto and colleagues showed that decreased restingstate functional connectivity between the frontal and parietal cortex, especially in the left side, was related to executive dysfunction in PD [59]. Interestingly, recent technological advances allowed for the development of portable, wearable, and wireless EEG headsets [60-62]. These inexpensive and easy-to-use EEG devices, with few channels and/or dry-electrodes, could be interesting for the evaluation of EFs outside of the laboratory in real-world environments. However, additional studies need to be performed to validate their use to evaluate EFs.

In light of all these advantages and innovations, the integration of immersive, virtual, or $360^{\circ}$ environments has the potential to simultaneously evaluate different components of executive functioning in a real-life setting via the use of ETs and EEGs. To date, only a few studies have integrated these methods, focusing mainly on executive dysfunctions in developmental age $[63,64]$.

Our work evaluates the convergent validity, usability, and efficacy of the EXecutiveFunctions Innovative Tool $360^{\circ}$ (EXIT $360^{\circ}$ ) to assess EFs in Parkinson's disease. This $360^{\circ}$ instrument will consist of a new $360^{\circ}$ task for EFs delivered via a technological device: a head-mounted display (HDM) that integrates an ET and an EEG.

The EXIT $360^{\circ}$ assessment tool will go beyond the effectiveness of standard tests, VR-based tools, or ET and EEG studies by combining different components and data for a multidimensional and multicomponent assessment of executive functioning with high clinical usability and ecological validity.

\section{Materials and Methods}

\subsection{Participants}

Following the sample-size calculation reported in the Statistical Analysis section, the sample will consist of 46 participants to guarantee optimal statistical power. Specifically, the study will include 25 individuals with Parkinson's disease (PD group), and 25 healthy controls (HC group) matched for age and education. Individuals with PD will be consecutively recruited from the Neurorehabilitation Unit of IRCCS, Fondazione Don Carlo Gnocchi ONLUS. All participants will have to show the following inclusion criteria: (a) age between 18 and 90 years; (b) education $\geq 5$ (primary school); (c) absence of overt dementia as determined by the Montreal Cognitive Assessment [65] (MoCA score $\geq 17.54$, cut-off of normality), corrected for age and years of education according to Italian normative data [66]; and (d) ability to provide written, signed informed consent. In addition, patients will have also to meet the following inclusion criteria: (a) Parkinson's disease according to MDS criteria [67]; (b) mild to moderate disease staging, with scores $<3$ on the Hoehn and Yahr scale; and (c) deficits in EFs confirmed by documented neurological and neuropsychological evaluation. Exclusion criteria will include: (a) severe hearing or visual impairment that could compromise the assessment with the new tool; and (b) major systemic, psychiatric, or other neurological illnesses. Particular attention will be used to exclude patients who experience visual hallucinations or suffer from vertigo.

The study was approved by the "Fondazione Don Carlo Gnocchi-Milan" Ethics Committee on 7 April 2021, project identification code 09_07/04/2021. The examiner will provide to all participants a complete explanation of the purpose and risk of the study before they sign a written informed consent based on the revised Declaration of Helsinki (2013). 


\subsection{Procedure of Study}

The study will involve four steps: (a) introduction phase; (b) pretask evaluation; (c) EXIT $360^{\circ}$ session; and(d) post-task evaluation. All studies will be conducted in a one-session evaluation at IRCCS Fondazione Don Carlo Gnocchi ONLUS in Milan.

\section{A. Introduction Phase}

Before study initiation, participants will receive a complete explanation of the study and sign the written informed consent. After that, the examiners will collect participants socio-demographic data (e.g., age, sex, education level, and occupation) and technological expertise. Specifically, the participants will be asked to evaluate their perceived level of familiarity and competence with technologies (e.g., tablet, smartphone, computer, internet, social network, and videogames). To test their level of familiarity with technologies, we will administer an ad hoc questionnaire using a 5-point scale (from "never" to "everyday") that evaluates "How often in the last year, have you happened to use ... ". Moreover, the competence scale will consist of a 5-point scale (from "not at all" to "very much") to investigate "How competent do you feel to use ... ".

\section{B. Pretask Evaluation}

Participants will undergo a conventional paper-and-pencil neuropsychological assessment to obtain their global cognitive profile, focusing mainly on executive functioning (pretask evaluation).

The global cognitive level will be evaluated with the MoCA [65], a sensitive screening tool for detecting mild cognitive impairment. As regards executive profile, participants will complete a battery of tests to determine EFs, including the Trail Making Test (in two specific subtests: TMT-A and TMT-B) [10], phonemic verbal fluency task (F.A.S.) [68], Stroop Test [69], Digit Span Backward [70], Frontal Assessment Battery (FAB) [71,72], Attentive Matrices [73], and Progressive Matrices of Raven [74-76]. Table 1 gives a detailed description of the different EFs evaluated by each neuropsychological test mentioned above.

Table 1. Pretask evaluation: list of traditional neuropsychological tests for the assessment of EFs.

\begin{tabular}{cc}
\hline Name & Executive Function \\
\hline Trail Making Test & Visual attention \\
\hline Verbal fluency & Task switching \\
\hline Stroop Test & Inhibition \\
\hline Digit Span Backward & Working memory \\
\hline Frontal Assessment Battery & Abstraction \\
& Cognitive flexibility \\
& $\begin{array}{c}\text { Motor programming/planning } \\
\text { Interference sensitivity } \\
\text { Inhibition control }\end{array}$ \\
\hline Attentive Matrices & $\begin{array}{c}\text { Visual search } \\
\text { Selective Attention }\end{array}$ \\
\hline Progressive Matrices of Raven & Sustained and selective attention \\
Reasoning
\end{tabular}

\section{EXIT $360^{\circ}$ Session}

Participants will undergo an evaluation of about 15-20 min with the EXecutivefunction Innovative Tool $360^{\circ}$ (EXIT $360^{\circ}$ ). The EXIT $360^{\circ}$ is a new tool for the assessment of EFs delivered via an innovative technological device: an HDM that integrates an ET and an EEG. This technological device will allow participants to be immersed in $360^{\circ}$ environments similar to real situations that they experience from a first-person perspective. 


\section{EXIT $360^{\circ}$ : A Complete Description of This EXecutive-Functions Innovative Tool}

EXIT $360^{\circ}$ aims to provide a complete evaluation of executive functioning, engaging participants in a "game for health" delivered via smartphones, in which they must perform several subtasks in $360^{\circ}$ environments. EXIT $360^{\circ}$ was based on three fundamental concepts for complete and integrated assessment: (1) ecological validity; (2) multicomponent assessment; and (3) clinical usability [77].

In light of the importance of evaluating EFs in real life (ecological validity), EXIT $360^{\circ}$ involves domestic environments such as the kitchen, bedroom, and living room. In these different environments, the subjects must perform seven subtasks representing everyday-life situations and assignments.

An evaluation of the challenges faced by the subjects in their environments can provide insight into ways to optimize rehabilitation. Moreover, EXIT $360^{\circ}$ will allow the clinician to obtain information about executive functioning while the participants are performing everyday tasks in an environment that reproduces real-life context (clinical usability).

Unlike the previous VR-based assessment instruments (e.g., V-MET-supermarket), EXIT $360^{\circ}$ offers the subjects five different scenarios, in which they are asked to perform different subtasks that represent daily life assignments, depending on the environment in which they are immersed.

The $360^{\circ}$ environments of EXIT $360^{\circ}$ were developed with the Ricoh Theta S Digital Camera, which permits $360^{\circ}$ spherical imageries. The camera can capture a $360^{\circ}$ scene by stitching two $180^{\circ}$ scans via integrated software (resolution of $1792 \times 3584$ pixels). This allows for a presentation of an immersive $360^{\circ}$ experience directly on an HDM via a smartphone connected to the technological device.

The use of $360^{\circ}$ environments allows overcoming some technical limitations regarding the development of virtual environments. In fact, $360^{\circ}$ environments do not require specific technological skills or high costs (e.g., expensive software), as they consist of $360^{\circ}$ photos or videos that require a $360^{\circ}$ camera and free online applications ([78]. Moreover, some studies showed that VR could cause some negative effects, such as nausea and dizziness [28]. On the contrary, a preliminary study on individuals with PD has shown the complete absence of adverse events in $360^{\circ}$ environments [47].

\section{The Seven Subtasks of EXIT $360^{\circ}$}

In EXIT $360^{\circ}$, the participants' main goal is to exit the domestic path in the shortest possible time. To do this, participants must plan a strategy and overcome seven different steps (subtasks) of increasing complexity: (1) Let's Start; (2) Unlock the Door; (3) Choose the Person; (4) Turn On the Light; (5) Where Are the Objects?; (6) Solve the Rebus; and (7) Create the Sequence.

EXIT $360^{\circ}$ is designed to tap into and evaluate different components of executive functioning (multicomponent assessment) simultaneously and quickly. Each subtask evaluates one or more EFs, such as planning, decision making, problem solving, attention, and working memory (Table 2). The subtasks reproduce common scenarios of everyday life that require the subject to solve specific assignments in according to the instructions and requests of each subtask. To respond to these requests, the subject will have to choose between three or more "alternatives", which will allow them to solve the assignment in the best possible way and continue their journey.

Table 2 summarizes the seven subtasks involved in EXIT $360^{\circ}$ with the EFs evaluated by each subtask.

\section{Description of Seven Subtasks and $360^{\circ}$ Environments}

Task 1- "Let's Start": The subjects will be immersed in a completely neutral room. The participants will explore the environment until they see a map of a path. They will have to observe the map and choose from four proposed path alternatives, the one that allows them to complete getting to the exit in the shortest possible time. If the subjects plan a correct strategy, they will choose the alternative " 2 ". If the answer is correct, they will enter the house and start their journey. 
Table 2. Subtasks and related EFs.

\begin{tabular}{|c|c|c|c|}
\hline & Name & Place & Executive Function \\
\hline Task 1 & Let's Start & Neutral room & Planning \\
\hline Task 2 & Unlock the Door & Landing & Decision making \\
\hline Task 3 & Choose the Person & Living room & $\begin{array}{l}\text { Problem solving } \\
\text { Divided attention }\end{array}$ \\
\hline \multirow{2}{*}{ Task 4} & \multirow{2}{*}{ Turn On the Light } & \multirow{2}{*}{ Corridor } & Problem solving \\
\hline & & & Decision making \\
\hline \multirow{4}{*}{ Task 5} & \multirow{4}{*}{ Where Are the Objects? } & \multirow{4}{*}{ Bedroom } & Visual searching \\
\hline & & & Selective attention \\
\hline & & & Reasoning \\
\hline & & & Problem solving \\
\hline \multirow{3}{*}{ Task 6} & \multirow{3}{*}{ Solve the Rebus } & \multirow{3}{*}{ Bedroom } & Planning \\
\hline & & & Reasoning \\
\hline & & & Problem solving \\
\hline Task 7 & Create the Sequence & Kitchen & Working memory \\
\hline
\end{tabular}

Task 2- “Unlock the Door": the participants will be immersed in a $360^{\circ}$ landing with a closed door. The neuropsychologist will tell the subjects that they must open the door to continue their journey and to enter the house. While exploring the environment, the subjects will see three 3D objects appear in the hall (i.e., key, drill, and telephone). They will have to choose between the three options to find the best one to open the door (decision making). If the participant makes the correct choice, they will continue their journey and enter a living room full of people.

Task 3-"Choose the Person": this task is set in a living room with five people inside who are doing different activities. Specifically, a man is reading a book sitting on a chair; two people (mother and child) are sitting on the sofa and chatting while watching television; and a woman is sitting at the table and writing in her diary, while a girl is sitting next to her and working with a computer. The neuropsychologist will ask the subjects to explore the room and give them the instruction, "One of these people has a clue that allows you to move forward on your path", followed by a description of the person to find. Only by focusing on the whole description (divided attention), will the subject be able to correctly select the person (the woman who is writing in her diary) to continue.

Task 4- “Turn On the Light": the subject will enter a long corridor full of objects (e.g., table, pictures, and ornaments). The subject will be asked to explore the environment, but at some point, the corridor will become completely dark. The subject will be told "It's all dark! The power went out. Here are four objects that could help you: you can only choose one". In front of the subjects, four objects will appear: a torch, an unlit candle, a ball, and a lamp. If the subjects give the correct answer (torch), the room will light up again: "The light is back! We can continue with our journey".

Task 5-“Where Are the Objects?": the subject will find himself immersed in a bedroom with many different pieces of furniture: a bed, two bedside tables, a wardrobe, a chair, and a dresser (Figure 1). Above each item, various objects will be scattered: candles, pillows, soft toys, clothing, lamps, blankets, glasses, and telephones. The subject will be asked to identify the piece of furniture on which all these four objects are placed together: lamp, soft toy, blanket, and telephone. Individual objects will be found on throughout, but only the dresser will have all of them. 


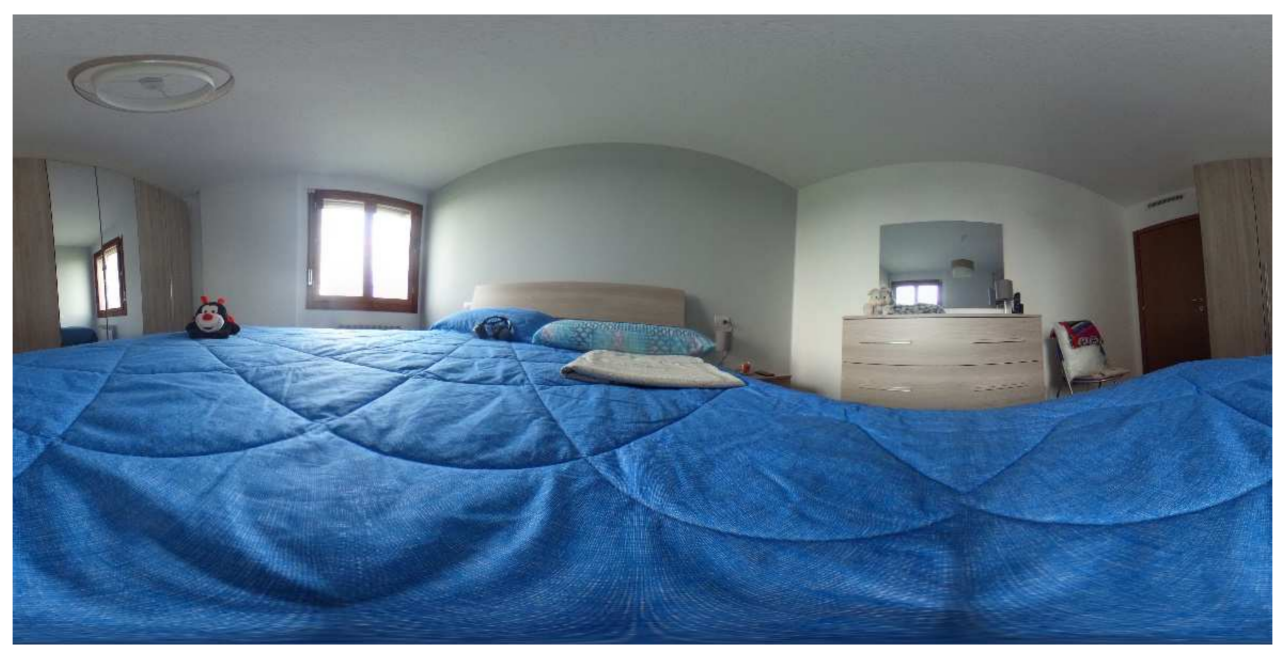

Figure 1. Task 5: $360^{\circ}$ environment that represents the bedroom.

Task 6-"Solve the Rebus": the subject will be immersed in another bedroom. To leave this room, the subject will be asked to complete a rebus that will appear on the wall. Firstly, the subject will see a rebus consisting of many tiles, with each tile containing both a number and a geometric shape of different colours. Next to these tiles, a blank tile will be inserted containing two question marks for the subject to fill in. Then, a series of response alternatives will appear near to rebus, and the subject will have to choose from them. If they choose the correct one, they can explore the last room in the house, the kitchen.

Task 7-“Create the Sequence": this task represents the last room of the house, the kitchen. In this room, the subjects will see an exit door that must be opened with a numerical combination. A series of five numbers will appear in the room, one after the other, on top of a black sofa (Figure 2). The examiner will say to the subject: "I ask you to read the numbers and try to memorize them. Our goal is to unlock the door to exit. The combination is formed by the series of numbers you will see but backwards, from last to first. If you see 235 , you will have to say 532 . What is the correct combination?" If the sequence shown is correct, the same initial map will appear with the words "GOOD, NOW YOU ARE HERE!" with all path and rooms coloured.

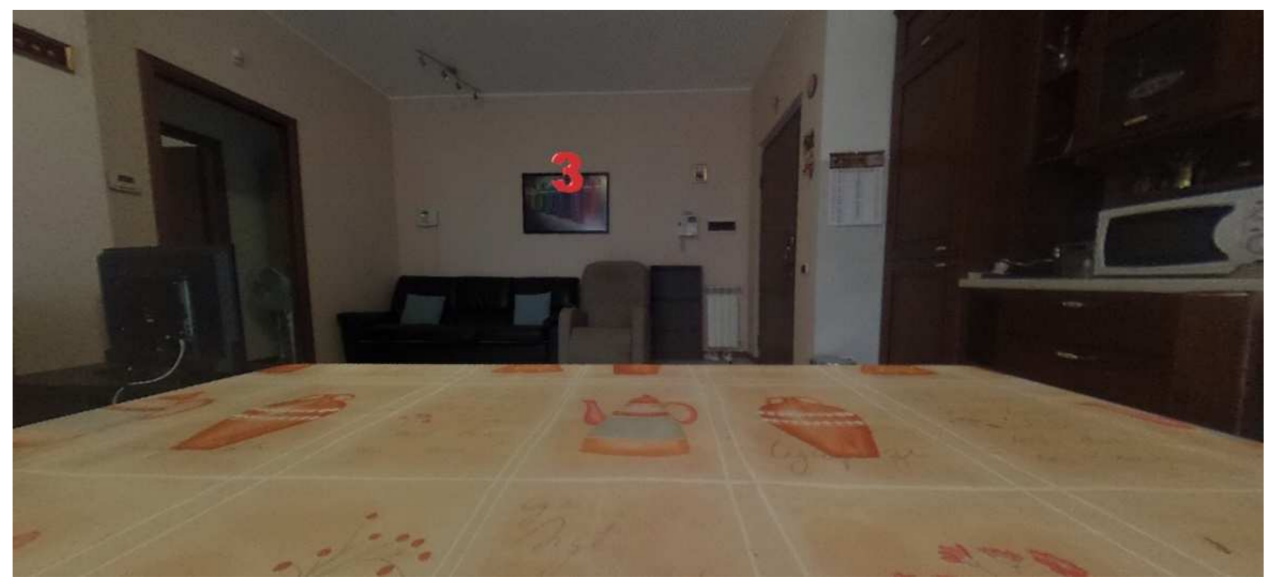

Figure 2. The representation of Task 7 : the $360^{\circ}$ kitchen showing one of the series numbers.

\section{Evaluation Procedure}

The neuropsychologist will begin the administration by inviting the participant to sit on a swivel chair and wear the HDM. Before wearing the HDM, the examiner will ask participants to keep their eyes closed. In the case of presbyopia, participants will wear their glasses. 
Before starting the evaluation task, the participant will undergo a phase (3 min) aimed at familiarizing them with the technology and observing potential side effects (e.g., dizziness, nausea). If side effects occur, the examiner will immediately stop the test. After wearing the HDM, the examiner will instruct the participant to open their eyes, and simultaneously the examiner will start a timer and begin audio recording. Participants will be completely immersed in a neutral $360^{\circ}$ environment that represents a living room, including a table with a plant, a sofa, various chairs, and objects spread throughout the room (Figure 3). First, the examiner will ask participants to explore the environments freely.

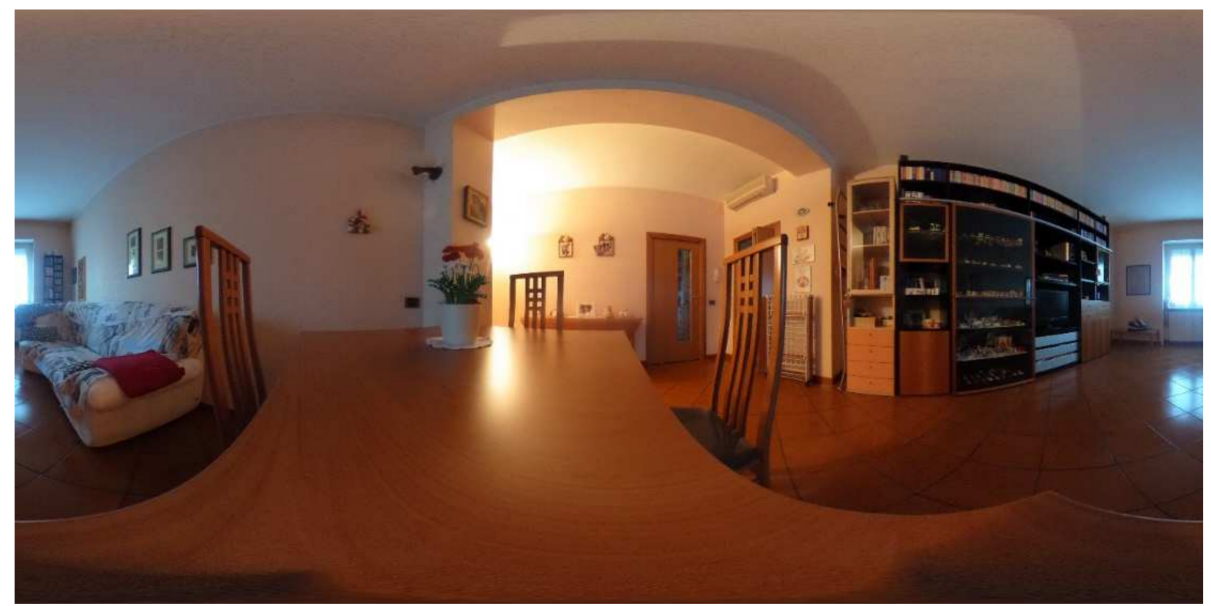

Figure 3. Example of neutral $360^{\circ}$ environment that represents a living room.

Then, they will ask the participant to find three specific objects in the scene: a plant, red blanket, or pictures (e.g., "Let's search for the plant. Where is the plant?"). Upon completion of the familiarization phase, participants will be asked to close their eyes again.

The experimental session will begin with time registration (in seconds) and audio recording coinciding with the examiner's instruction "Open your eyes". At the beginning of the task, the subjects will be immersed in a $360^{\circ}$ environment that represents a neutral room. They will receive the following instruction: "You are about to enter a house. Your goal is to get out of this house in the shortest time possible. To exit you will have to complete a path and a series of 'tasks' that you will encounter along your way. Are you ready to start?" After giving the initial instruction, the neuropsychologist will accompany and guide the participant along the entire path: they will provide subtask instructions, manage the passage from one room to another, and collect the subjects' answers. During the journey, the subject will have to freely explore the $360^{\circ}$ environment, simply through the movement of the head, as in real situations [79]. As previously stated, the participant will have to perform seven subtasks. In each level, the subject will be asked to answer, choosing between three or more "alternatives", according to the task's request. The researcher will record all the subject's responses: if the subject chooses a wrong alternative, the test will be immediately stopped.

The following indices will be calculated:

(1). Correct answer for each subtask (and total score);

(2). Subtask reaction time: the time (in seconds) from the start of a subtask until the participant provides an answer. The maximum time allowed will be $180 \mathrm{~s}$ (as suggested by [47]);

(3). Total reaction time: The time in seconds registered from the examiner's instruction until the participant provides the last correct answer.

Moreover, the HDM will allow the detection of nonverbal indices related to EFs by collecting eye movements (saccadic and antisaccadic movements, and fixations) by ET and electrical activity of prefrontal cortex by EEG signals (six channels, 24 bit). 


\section{Post-Task Evaluation}

At the end of EXIT $360^{\circ}$ task evaluation, the subject will have to rate the quality of the experience associated with its use through an ad hoc questionnaire that assesses perceived levels of challenge and skill, appreciation, and sense of presence experienced (post-task evaluation). Specifically, the questionnaire will involve:

(a) Three items from the Flow Short Scale (5-point scale, from low to high) to assess level of skills in coping with the task, challenges, and the perceived challenge-skill balance, respectively [80].

(b) Five items (6-point scale) from the subscale "Enjoyment" of the Intrinsic Motivation Inventory (IMI) [81] to evaluate participants' appreciation of the proposed activity, including the item "This activity was fun to do".

(c) Three items of the Slater-Usoh-Steed Questionnaire [82] (7-point questionnaire) to evaluate the sense of presence, assessing the measure regarding whether: (1) to be in the $360^{\circ}$ scene; (2) the $360^{\circ}$ scene became the dominant reality; and (3) the $360^{\circ}$ scene was remembered as a place.

Moreover, the participant will evaluate the level of usability of technological device on the System Usability Scale (SUS) [83] (5-point scale, from "disagree entirely" to "agree totally").

\subsection{Statistical Analysis}

The sample-size calculation was performed with $G$ power software.

F test-ANOVA: Repeated measures, between factors

Analysis: A priori: Compute required sample size

\begin{tabular}{|c|c|c|c|}
\hline \multirow[t]{6}{*}{ Input: } & Effect size f & $=$ & 0.369 \\
\hline & $\alpha$ err prob & $=$ & 0.05 \\
\hline & Power (1- $\beta$ err prob) & $=$ & 0.80 \\
\hline & Number of groups & $=$ & 2 \\
\hline & Number of measurements & $=$ & 2 \\
\hline & Corr among rep measures & $=$ & 0.5 \\
\hline \multirow[t]{6}{*}{ Output: } & Noncentrality parameter $\lambda$ & $=$ & 8.3512080 \\
\hline & Critical F & $=$ & 4.0617065 \\
\hline & Numerator df & $=$ & 1.0000000 \\
\hline & Denominator df & $=$ & 46.0000000 \\
\hline & Total sample size & $=$ & 46 \\
\hline & Actual power & $=$ & 0.8068335 \\
\hline
\end{tabular}

The Effect size obtained from the validation study of the PIT $360^{\circ}$ by Serino and colleagues was chosen as a benchmark, as the studies are similar in terms of methods and materials (e.g., experimental procedure, $360^{\circ}$ environments, and clinical population involved).

Descriptive statistics of the sample will include frequencies, median and interquartile range (IQR) for categorical variables, and mean and standard deviation (SD) for continuous measures. The normality of data distribution will be assessed using the KolmogorovSmirnov test. An ANOVA between-group comparison will be run to assess significant differences between patients and healthy controls in traditional neuropsychological assessment and immersive experience evaluation indices. Specifically, the statistical analysis will have to highlight possible difference in verbal (correct answer and reaction time) and nonverbal indices (antisaccadic movements, fixations, and electrical activity of prefrontal cortex). A Pearson correlation will be applied to compare both the nonverbal with verbal indices and traditional neuropsychological tests with the verbal outcomes of the immersive experience. A Spearman's correlation will be applied to compare the usability tests and technological experience questionnaire scores with EXIT $360^{\circ}$ outcomes. An ANOVA between-group comparison will be run to check significant differences between patients 
and healthy controls in evaluating the usability of the mobile-powered headset. Finally, descriptive statistics will be conducted to evaluate the user experience, perceived levels of challenge and skill, appreciation, and sense of presence experienced while performing the EXIT $360^{\circ}$. All statistical analyses will be performed using Jamovi 1.6.7. ROC curves will evaluate the specificity and sensitivity of all the tests administered. These statistical analyses will be performed using the Statistical Package for the Social Sciences for Windows (IBM Corp, Armonk, NY, USA), version 23. Nonlinear stochastic approximation (i.e., machine-learning) methods will be used to compare the classification accuracy of traditional neuropsychological assessments versus the EXIT $360^{\circ}$ indices for classifying participants into either the "Individuals with PD" or "Healthy Controls" groups. Different machine-learning algorithms will be employed: a logistic regression classification algorithm and a random forest classification. All these analyses will be computed using Python 3.4 with the Orange 3.3.5 data-mining suite, which is freely available as open-source code (https:/ / github.com/biolab / orange3, accessed on 23 July 2021).

\section{Conclusions}

Executive dysfunction is one of the major clinical nonmotor symptoms in early-stage nondemented PD [4], and is particularly disabling due to its high negative impact on daily functioning and quality of life [6-8]. Since EFs play a key role in everyday life and independent functioning $[84,85]$, identifying early strategies functional to the ecological evaluation of EFs is crucial to achieve optimal PD management. The ecological limitations of traditional neuropsychological batteries and numerous difficulties in administering tests in real-life scenarios have led to the increasing use of technological instruments, including virtual reality and $360^{\circ}$ enviroment-based tools for the assessment of EFs in reallife. Advances in $360^{\circ}$ technologies have allowed participants to be evaluated in virtual scenarios that they experience from a first-person perspective, overcoming some limitations (technical and clinical) regarding VR. A preliminary study that used a $360^{\circ}$-based tool (PIT $360^{\circ}$ ) for assessment of executing functioning (only visual-searching component) showed that PIT $360^{\circ}$ could distinguish individuals with PD from controls.

EXIT $360^{\circ}$ was designed to obtain information about executive-functioning components while the participants perform everyday tasks in $360^{\circ}$ environments that reproduce different real-life contexts. Our study aims to evaluate the efficacy and usability of EXIT $360^{\circ}$ as an innovative and ecologically valid tool for the evaluation of the EFs in PD. First, it is expected that all participants will evaluate EXIT $360^{\circ}$ as usable, engaging, and challenging, and they will show a high sense of presence while immersed in EXIT $360^{\circ}$. Secondly, we suppose that EXIT $360^{\circ}$ will reveal different performances in individuals with PD compared to HC. Specifically, in line with previous evidence, we expect patients to have more difficulty in responding correctly to subtasks, have delayed exit times from the house, take longer to provide a correct interpretation of the proposed scene, and be more prone to distractor interference. Moreover, patients should show greater difficulty in focusing on the most critical components for a correct interpretation of the scene. In addition, we expect to find a correlation between conventional neuropsychological tests of executive functions and performance on PIT $360^{\circ}$. In other words, we expect to see a convergent validity between the standard tests and EXIT $360^{\circ}$. In this way, EXIT $360^{\circ}$ could be considered a quick, ecological, and useful screening tool capable of evaluating different aspects of dysexecutive disability in individuals with PD. Further, through the analyses, we expect the results obtained by the classifiers to indicate the potential of the EXIT $360^{\circ}$ evaluation in distinguishing between individuals with PD and HC. It will be interesting to see if EXIT $360^{\circ}$ will have a greater capacity in predicting patients in the PD group compared to a traditional neuropsychological assessment. Furthermore, thanks to an innovative technological device that integrates an ET and EEG, we expect to find, in line with the literature, differences between PD and HC in activating the frontal cortex, and in the antisaccadic eye movements and the number of fixations. 
The validation of EXIT $360^{\circ}$ as an innovative assessment tool for EFs in PD will allow a quick, ecological, and useful $360^{\circ}$-based instrument that is easily accessible and that will radically transform the assessment experience for both the clinic and the patient. The clinician will obtain faster, multicomponent, and multidomain evaluations. EXIT $360^{\circ}$ will allow clinicians to simultaneously and quickly (15-20 min) collect data on several components of executive functioning through verbal responses (choosing between three or more "options") and reaction time. Moreover, the use of the easy-to-use technological device for delivering of the $360^{\circ}$ environments and subtasks of EXIT $360^{\circ}$ will allow collecting nonverbal data by ET (e.g., saccadic and antisaccadic movements, and fixations) and EEG (i.e., the electrical activity of prefrontal cortex). Interestingly, EXIT $360^{\circ}$ will ensure that clinicians can obtain information about executive functioning while participants are performing everyday tasks in environments that reproduce real-life contexts, testing complex functions of daily life enjoyably. On the other hand, the patient will be involved in a short task (vs. a long and complicated evaluation) that can be experienced as a "game for health", increasing engagement and lowering the level of emotional charge that a neuropsychological assessment can entail. Moreover, this tool will allow participants to receive immediate feedback on their performance. Finally, unlike most VR-based tools, EXIT $360^{\circ}$ delivered via the innovative technological device will be a portable device suitable for clinical settings and for individuals with motor difficulties who cannot walk. Compared to other technological devices, this device is easily transportable, so the evaluation can also be performed in the patient's room or house, overcoming logistical challenges related to bringing a patient into the clinic.

In conclusion, EXIT $360^{\circ}$ will go beyond the effectiveness of standard tests, VRbased tools, or ET and EEG studies by combining different components and data for a multidimensional and multicomponent assessment of executive functioning with high clinical usability and ecological validity.

Author Contributions: F.B. (Francesca Borgnis) and P.C. developed the new EXecutive-Functions Innovative Tool $360^{\circ}$; P.C. and G.R. supervised the sections on virtual reality, the eye tracker, and the EEG.; E.P. and F.R. supervised the section regarding executive functioning. F.B. (Francesca Baglio) and M.M. supervised the section regarding Parkinson's disease. F.B. (Francesca Borgnis) wrote the manuscript under the final supervision of F.B. (Francesca Baglio) and P.C. All authors have read and agreed to the published version of the manuscript.

Funding: This research received no external funding.

Institutional Review Board Statement: The study was conducted according to the guidelines of the Declaration of Helsinki, and approved by "Fondazione Don Carlo Gnocchi-Milan" Ethics Committee on 7th April 2021, project identification code 09_07/04/2021.

Informed Consent Statement: Informed consent will be obtained from all subjects involved in the study.

Data Availability Statement: Not applicable.

Conflicts of Interest: The authors declare no conflict of interest.

\section{References}

1. Aarsland, D.; Creese, B.; Politis, M.; Chaudhuri, K.R.; Weintraub, D.; Ballard, C. Cognitive Decline in Parkinson Disease. Nat. Rev. Neurol. 2017, 13, 217-231. [CrossRef] [PubMed]

2. Fengler, S.; Liepelt-Scarfone, I.; Brockmann, K.; Schäffer, E.; Berg, D.; Kalbe, E. Cognitive Changes in Prodromal Parkinson's Disease: A Review. Mov. Disord. 2017, 32, 1655-1666. [CrossRef]

3. Fang, C.; Lv, L.; Mao, S.; Dong, H.; Liu, B. Cognition Deficits in Parkinson's Disease: Mechanisms and Treatment. Park. Dis. 2020, 2020, 1-11. [CrossRef] [PubMed]

4. Kudlicka, A.; Clare, L.; Hindle, J.V. Executive Functions in Parkinson's Disease: Systematic Review and Meta-analysis. Mov. Disord. 2011, 26, 2305-2315. [CrossRef] [PubMed]

5. Dirnberger, G.; Jahanshahi, M. Executive Dysfunction in P Arkinson's Disease: A Review. J. Neuropsychol. 2013, 7, 193-224. [CrossRef] 
6. Leroi, I.; McDonald, K.; Pantula, H.; Harbishettar, V. Cognitive Impairment in Parkinson Disease: Impact on Quality of Life, Disability, and Caregiver Burden. J. Geriatr. Psychiatry Neurol. 2012, 25, 208-214. [CrossRef]

7. Lawson, R.A.; Yarnall, A.; Duncan, G.W.; Breen, D.P.; Khoo, T.K.; Williams-Gray, C.; Barker, R.A.; Collerton, D.; Taylor, J.-P.; Burn, D. Cognitive decline and quality of life in incident Parkinson's disease: The role of attention. Park. Relat. Disord. 2016, $27,47-53$. [CrossRef]

8. Barone, P.; Erro, R.; Picillo, M. Quality of Life and Nonmotor Symptoms in Parkinson's Disease. Int. Rev. Neurobiol. 2017, 133, 499-516. [CrossRef]

9. Nelson, H.E. A Modified Card Sorting Test Sensitive to Frontal Lobe Defects. Cortex 1976, 12, 313-324. [CrossRef]

10. Reitan, R.M. Trail Making Test: Manual for Administration and Scoring; Reitan Neuropsychology Laboratory: Tucson, AZ, USA, 1992.

11. Shallice, T.; Burgess, P.W. Deficits in Strategy Application Following Frontal Lobe Damage in Man. Brain 1991, 114, 727-741. [CrossRef]

12. Goldstein, G. Functional Considerations in Neuropsychology; Gr Press/St Lucie Press, Inc.: Boca Raton, FL, USA, 1996.

13. Klinger, E.; Chemin, I.; Lebreton, S.; Marie, R.M. A Virtual Supermarket to Assess Cognitive Planning. Annu. Rev. CyberTher. Telemed. 2004, 2, 49-57.

14. Burgess, P.W.; Alderman, N.; Forbes, C.; Costello, A.; Coates, L.M.A.; Dawson, D.R.; Anderson, N.D.; Gilbert, S.J.; Dumontheil, I.; Channon, S. The Case for the Development and Use of "Ecologically Valid" Measures of Executive Function in Experimental and Clinical Neuropsychology. J. Int. Neuropsychol. Soc. 2006, 12, 194-209. [CrossRef]

15. Chaytor, N.; Schmitter-Edgecombe, M.; Burr, R. Improving the Ecological Validity of Executive Functioning Assessment. Arch. Clin. Neuropsychol. 2006, 21, 217-227. [CrossRef] [PubMed]

16. Chan, R.C.K.; Shum, D.; Toulopoulou, T.; Chen, E.Y.H. Assessment of Executive Functions: Review of Instruments and Identification of Critical Issues. Arch. Clin. Neuropsychol. 2008, 23, 201-216. [CrossRef] [PubMed]

17. Sirigu, A.; Zalla, T.; Pillon, B.; Grafman, J.; Agid, Y.; Dubois, B. Selective Impairments in Managerial Knowledge Following Pre-Frontal Cortex Damage. Cortex 1995, 31, 301-316. [CrossRef]

18. Chaytor, N.; Schmitter-Edgecombe, M. The Ecological Validity of Neuropsychological Tests: A Review of the Literature on Everyday Cognitive Skills. Neuropsychol. Rev. 2003, 13, 181-197. [CrossRef] [PubMed]

19. Rand, D.; Rukan, S.B.A.; Weiss, P.L.; Katz, N. Validation of the Virtual MET as an Assessment Tool for Executive Functions. Neuropsychol. Rehabil. 2009, 19, 583-602. [CrossRef]

20. Bailey, P.E.; Henry, J.D.; Rendell, P.G.; Phillips, L.H.; Kliegel, M. Dismantling the "Age-Prospective Memory Paradox": The Classic Laboratory Paradigm Simulated in a Naturalistic Setting. Q. J. Exp. Psychol. 2010, 63, 646-652. [CrossRef]

21. Liao, Y.Y.; Tseng, H.Y.; Lin, Y.J.; Wang, C.J.; Hsu, W.C. Using Virtual Reality-Based Training to Improve Cognitive Function, Instrumental Activities of Daily Living and Neural Efficiency in Older Adults with Mild Cognitive Impairment. Eur. J. Phys. Rehabil. Med. 2020, 56, 47-57. [CrossRef]

22. Herault, R.C.; Lincke, A.; Milrad, M.; Forsgärde, E.-S.; Elmqvist, C. Using 360-Degrees Interactive Videos in Patient Trauma Treatment Education: Design, Development and Evaluation Aspects. Smart Learn. Environ. 2018, 5, 1-15. [CrossRef]

23. Carlotta Olivetti, E.; Violante, M.G.; Vezzetti, E.; Marcolin, F.; Eynard, B. Engagement Evaluation in a Virtual Learning Environment via Facial Expression Recognition and Self-Reports: A Preliminary Approach. Appl. Sci. 2020, 10, 314. [CrossRef]

24. Ha, H.-G.; Hong, J. Augmented Reality in Medicine. Hanyang Med. Rev. 2016, 36, 242-247. [CrossRef]

25. Campbell, Z.; Zakzanis, K.K.; Jovanovski, D.; Joordens, S.; Mraz, R.; Graham, S.J. Utilizing Virtual Reality to Improve the Ecological Validity of Clinical Neuropsychology: An FMRI Case Study Elucidating the Neural Basis of Planning by Comparing the Tower of London with a Three-Dimensional Navigation Task. Appl. Neuropsychol. 2009, 16, 295-306. [CrossRef]

26. Bohil, C.J.; Alicea, B.; Biocca, F.A. Virtual Reality in Neuroscience Research and Therapy. Nat. Rev. Neurosci. 2011, 12, 752-762. [CrossRef]

27. Parsons, T.D.; Courtney, C.G.; Arizmendi, B.; Dawson, M. Virtual Reality Stroop Task for Neurocognitive Assessment. Stud. Health Technol. Inform. 2011, 163, 433-439. [CrossRef] [PubMed]

28. Parsons, T.D. Virtual Reality for Enhanced Ecological Validity and Experimental Control in the Clinical, Affective and Social Neurosciences. Front. Hum. Neurosci. 2015, 9, 660. [CrossRef] [PubMed]

29. Riva, G. Virtual Reality in Neuro-Psycho-Physiology: Cognitive, Clinical and Methodological Issues in Assessment and Rehabilitation; IOS Press: Amsterdam, The Netherlands, 1997; Volume 44.

30. Riva, G. Psicologia Dei Nuovi Media, Il Mulino. Bologna, Italy, 2004. Available online: https://www.researchgate.net/ publication/296198198_Psicologia_dei_nuovi_media_Azione_presenza_identita_e_relazioni (accessed on 23 July 2021).

31. Rizzo, A.A.; Buckwalter, J.G.; McGee, J.S.; Bowerly, T.; van der Zaag, C.; Neumann, U.; Thiebaux, M.; Kim, L.; Pair, J.; Chua, C. Virtual Environments for Assessing and Rehabilitating Cognitive/Functional Performance a Review of Projects at the USC Integrated Media Systems Center. Presence Teleoperators Virtual Environ. 2001, 10, 359-374. [CrossRef]

32. Pratt, D.R.; Zyda, M.; Kelleher, K. Virtual reality: In the mind of the beholder. In Proceedings of the Computer IEEE, San Francisco, CA, USA, 5-9 March 1995; pp. 17-19.

33. Climent, G.; Banterla, F.; Iriarte, Y. Virtual reality, technologies and behavioural assessment. In AULA, Ecological Evaluation of Attentional Processes; Nesplora San Sebastian: Donostia-San Sebastian, Spain, 2010; pp. 19-28.

34. Riva, G. Virtual Reality: An Experiential Tool for Clinical Psychology. Br. J. Guid. Counc. 2009, 37, 337-345. [CrossRef]

35. Alderman, M.K. Motivation for Achievement: Possibilities for Teaching and Learning; Routledge: London, UK, 2013. 
36. Armstrong, C.M.; Reger, G.M.; Edwards, J.; Rizzo, A.A.; Courtney, C.G.; Parsons, T.D. Validity of the Virtual Reality Stroop Task (VRST) in Active Duty Military. J. Clin. Exp. Neuropsychol. 2013, 35, 113-123. [CrossRef]

37. Cipresso, P.; Meriggi, P.; Carelli, L.; Solca, F.; Poletti, B.; Lulé, D.; Ludolph, A.C.; Silani, V.; Riva, G. Cognitive Assessment of Executive Functions Using Brain Computer Interface and Eye-Tracking. EAI Endorsed Trans. Ambient Syst. 2013, 1, e4. [CrossRef]

38. Klinger, E.; Chemin, I.; Lebreton, S.; Marié, R.-M. Virtual Action Planning in Parkinson's Disease: A Control Study. Cyberpsychol. Behav. 2006, 9, 342-347. [CrossRef]

39. Wiederhold, B.K.; Riva, G.; Kim, S.I. Annual Review of Cybertherapy and Telemedicine 2010 Introduction. In Studies in Health Technology and Informatics; IOS Press: Clifton, VA, USA, 2010; Volume 154.

40. Cipresso, P.; Albani, G.; Serino, S.; Pedroli, E.; Pallavicini, F.; Mauro, A.; Riva, G. Virtual Multiple Errands Test (VMET): A Virtual Reality-Based Tool to Detect Early Executive Functions Deficit in Parkinson's Disease. Front. Behav. Neurosci. 2014, 8, 405. [CrossRef] [PubMed]

41. Serino, S.; Pedroli, E.; Cipresso, P.; Pallavicini, F.; Albani, G.; Mauro, A.; Riva, G. The Role of Virtual Reality in Neuropsychology: The Virtual Multiple Errands Test for the Assessment of Executive Functions in Parkinson's Disease. Intell. Syst. Ref. Libr. 2014, 68, 257-274. [CrossRef]

42. Monchi, O.; Petrides, M.; Doyon, J.; Postuma, R.B.; Worsley, K.; Dagher, A. Neural Bases of Set-Shifting Deficits in Parkinson's Disease. J. Neurosci. 2004, 24, 702-710. [CrossRef] [PubMed]

43. Raspelli, S.; Carelli, L.; Morganti, F.; Albani, G.; Pignatti, R.; Mauro, A.; Poletti, B.; Corra, B.; Silani, V.; Riva, G. A Neuro Vr-Based Version of the Multiple Errands Test for the Assessment of Executive Functions: A Possible Approach. J. Cyber Ther. Rehabil. 2009, 2, 299-314.

44. Wiederhold, B.K.; Reality, V.; Riva, G. Annual Review of Cybertherapy and Telemedicine 2010—Advanced Technologies in Behavioral, Social and Neurosciences. In Studies in Health Technology and Informatics; IOS Press: Clifton, VA, USA, 2010; Volume 154.

45. Azuma, T.; Cruz, R.F.; Bayles, K.A.; Tomoeda, C.K.; Montgomery, E.B., Jr. A Longitudinal Study of Neuropsychological Change in Individuals with Parkinson's Disease. Int. J. Geriatr. Psychiatry 2003, 18, 1043-1049. [CrossRef]

46. Janvin, C.C.; Aarsland, D.; Larsen, J.P. Cognitive Predictors of Dementia in Parkinson's Disease: A Community-Based, 4-Year Longitudinal Study. J. Geriatr. Psychiatry Neurol. 2005, 18, 149-154. [CrossRef]

47. Serino, S.; Baglio, F.; Rossetto, F.; Realdon, O.; Cipresso, P.; Parsons, T.D.; Cappellini, G.; Mantovani, F.; De Leo, G.; Nemni, R.; et al. Picture Interpretation Test (PIT) 360 : An Innovative Measure of Executive Functions. Sci. Rep. 2017, 7, 16000. [CrossRef]

48. Milgram, P.; Kishino, F. A Taxonomy of Mixed Reality Visual Displays. IEICE Trans. Inf. Syst. 1994, 77, 1321-1329.

49. Violante, M.G.; Vezzetti, E.; Piazzolla, P. Interactive Virtual Technologies in Engineering Education: Why Not $360^{\circ}$ Videos? Int. J. Interact. Des. Manuf. 2019, 13, 729-742. [CrossRef]

50. Rosci, C.; Sacco, D.; Laiacona, M.; Capitani, E. Interpretation of a Complex Picture and Its Sensitivity to Frontal Damage: A Reappraisal. Neurol. Sci. 2005, 25, 322-330. [CrossRef]

51. Luria, A.R.; Karpov, B.A.; Yarbuss, A.L. Disturbances of Active Visual Perception with Lesions of the Frontal Lobes. Cortex 1966, 2, 202-212. [CrossRef]

52. Mirsky, J.B.; Heuer, H.W.; Jafari, A.; Kramer, J.H.; Schenk, A.K.; Viskontas, I.V.; Neuhaus, J.; Miller, B.L.; Boxer, A.L. Anti-Saccade Performance Predicts Executive Function and Brain Structure in Normal Elders. Cogn. Behav. Neurol. Off. J. Soc. Behav. Cogn. Neurol. 2011, 24, 50. [CrossRef] [PubMed]

53. Ouerfelli-Ethier, J.; Elsaeid, B.; Desgroseilliers, J.; Munoz, D.P.; Blohm, G.; Khan, A.Z. Anti-Saccades Predict Cognitive Functions in Older Adults and Patients with Parkinson's Disease. PLoS ONE 2018, 13, e0207589. [CrossRef] [PubMed]

54. Clay, V.; König, P.; König, S.U. Eye Tracking in Virtual Reality. J. Eye Mov. Res. 2019, 12. [CrossRef]

55. Raz, N. Aging of the Brain and Its Impact on Cognitive Performance: Integration of Structural and Functional Findings. In The Handbook of Aging and Cognition; Lawrence Erlbaum Associates Publishers: Mahwah, NJ, USA, 2000.

56. Burke, S.N.; Barnes, C.A. Neural Plasticity in the Ageing Brain. Nat. Rev. Neurosci. 2006, 7, 30-40. [CrossRef] [PubMed]

57. Baddeley, A.; Wilson, B. Frontal Amnesia and the Dysexecutive Syndrome. Brain Cogn. 1988, 7, 212-230. [CrossRef]

58. Yu, Y.; Zhao, Y.; Si, Y.; Ren, Q.; Ren, W.; Jing, C.; Zhang, H. Estimation of the Cool Executive Function Using Frontal Electroencephalogram Signals in First-Episode Schizophrenia Patients. Biomed. Eng. Online 2016, 15, 131. [CrossRef]

59. Teramoto, H.; Morita, A.; Ninomiya, S.; Akimoto, T.; Shiota, H.; Kamei, S. Relation between Resting State Front-Parietal EEG Coherence and Executive Function in Parkinson's Disease. BioMed Res. Int. 2016, 2016, 1-6. [CrossRef]

60. Malechka, T.; Tetzel, T.; Krebs, U.; Feuser, D.; Graeser, A. Sbci-Headset-Wearable and Modular Device for Hybrid BrainComputer Interface. Micromachines 2015, 6, 291-311. [CrossRef]

61. Suresh, S.; Liu, Y.; Yeow, R.C.-H. Development of a Wearable Electroencephalographic Device for Anxiety Monitoring. J. Med. Device. 2015, 9, 030917. [CrossRef]

62. Abiri, R.; Borhani, S.; Sellers, E.W.; Jiang, Y.; Zhao, X. A Comprehensive Review of EEG-Based Brain-Computer Interface Paradigms. J. Neural Eng. 2019, 16, 11001. [CrossRef]

63. Bekele, E.; Member, S.; Wade, J.; Bian, D.; Fan, J.; Swanson, A.; Warren, Z.; Member, S. Multimodal adaptive social interaction in virtual environment (MASI-VR) for children with Autism spectrum disorders (ASD). In Proceedings of the 2016 IEEE Virtual Reality (VR), Greenville, SC, USA, 19-23 March 2016; pp. 121-130. 
64. Billeci, L.; Narzisi, A.; Tonacci, A.; Sbriscia-Fioretti, B.; Serasini, L.; Fulceri, F.; Apicella, F.; Sicca, F.; Calderoni, S.; Muratori, F. An Integrated EEG and Eye-Tracking Approach for the Study of Responding and Initiating Joint Attention in Autism Spectrum Disorders. Sci. Rep. 2017, 7, 1-13. [CrossRef] [PubMed]

65. Nasreddine, Z.S.; Phillips, N.A.; Bédirian, V.; Charbonneau, S.; Whitehead, V.; Collin, I.; Cummings, J.L.; Chertkow, H. The Montreal Cognitive Assessment, MoCA: A Brief Screening Tool for Mild Cognitive Impairment. J. Am. Geriatr. Soc. 2005, 53, 695-699. [CrossRef] [PubMed]

66. Santangelo, G.; Siciliano, M.; Pedone, R.; Vitale, C.; Falco, F.; Bisogno, R.; Siano, P.; Barone, P.; Grossi, D.; Santangelo, F. Normative Data for the Montreal Cognitive Assessment in an Italian Population Sample. Neurol. Sci. 2015, 36, 585-591. [CrossRef]

67. Postuma, R.B.; Berg, D.; Stern, M.; Poewe, W.; Olanow, C.W.; Oertel, W.; Obeso, J.; Marek, K.; Litvan, I.; Lang, A.E. MDS Clinical Diagnostic Criteria for Parkinson's Disease. Mov. Disord. 2015, 30, 1591-1601. [CrossRef] [PubMed]

68. Novelli, G.; Papagno, C.; Capitani, E.; Laiacona, M. Tre Test Clinici Di Memoria Verbale a Lungo Termine: Taratura Su Soggetti Normali. In Archivio di Psicologia, Neurologia e Psichiatria; Universita Cattolica del Sacro Cuore: Milan, Italy, 1986.

69. Stroop, J.R. Studies of Interference in Serial Verbal Reactions. J. Exp. Psychol. 1935, 18, 643. [CrossRef]

70. Monaco, M.; Costa, A.; Caltagirone, C.; Carlesimo, G.A. Forward and Backward Span for Verbal and Visuo-Spatial Data: Standardization and Normative Data from an Italian Adult Population. Neurol. Sci. 2013, 34, 749-754. [CrossRef] [PubMed]

71. Dubois, B.; Slachevsky, A.; Litvan, I.; Pillon, B. The FAB: A Frontal Assessment Battery at Bedside. Neurology 2000, 55, 1621-1626. [CrossRef]

72. Appollonio, I.; Leone, M.; Isella, V.; Piamarta, F.; Consoli, T.; Villa, M.L.; Forapani, E.; Russo, A.; Nichelli, P. The Frontal Assessment Battery (FAB): Normative Values in an Italian Population Sample. Neurol. Sci. 2005, 26, 108-116. [CrossRef]

73. Spinnler, H.; Tognoni, G. Standardizzazione e Taratura Italiana Di Tests Neuropsicologici. [Italian Normative Values and Standardization of Neuropsychological Tests]. Ital. J. Neurol. Sci. 1987, 6 (Suppl. 8), 1-20.

74. Raven, J.C. Progressive Matrices: Sets A, B, C, D, and E; University Press, HK Lewis: Hongkong, China, 1938.

75. Caffarra, P.; Vezzadini, G.; Zonato, F.; Copelli, S.; Venneri, A. A Normative Study of a Shorter Version of Raven's Progressive Matrices 1938. Neurol. Sci. 2003, 24, 336-339. [CrossRef] [PubMed]

76. Raven, J.C. Progressive Matrices: Sets A, AbB. In Board B. Forms; Progressive matrices; H. K. Lewis: London, UK, 1947.

77. Borgnis, F.; Baglio, F.; Pedroli, E.; Rossetto, F.; Riva, G.; Cipresso, P. A Simple and Effective Way to Study Executive Functions by Using $360^{\circ}$ Videos. Front. Neurosci. 2021, 15, 296. [CrossRef] [PubMed]

78. Parsons, T.D.; Phillips, A.S. Virtual Reality for Psychological Assessment in Clinical Practice. Pract. Innov. 2016, 1, 197-217. [CrossRef]

79. Serino, S.; Repetto, C. New Trends in Episodic Memory Assessment: Immersive 360 Ecological Videos. Front. Psychol. 2018, 9 , 1878. [CrossRef]

80. Engeser, S.; Rheinberg, F.; Vollmeyer, R.; Bischoff, J. Motivation, Flow-Erleben Und Lernleistung in Universitären Lernsettings. In Zeitschrift für Pädagogische Psychologie; Verlag Hans Huber, Hogrefe AG: Bern, Switzerland; Göttingen, Gemany, 2005; Volume 19, pp. 159-172.

81. Deci, E.L.; Eghrari, H.; Patrick, B.C.; Leone, D.R. Facilitating Internalization: The Self-determination Theory Perspective. J. Pers. 1994, 62, 119-142. [CrossRef]

82. Slater, M.; Sadagic, A.; Usoh, M.; Schroeder, R. Small-Group Behavior in a Virtual and Real Environment: A Comparative Study. In Presence Teleoperators Virtual Environ; MIT Press: Cambridge, UK, 2000; Volume 9, pp. 37-51. [CrossRef]

83. Brooke, J. SUS-A Quick and Dirty Usability Scale. Usability Eval. Ind. 1996, 189, 4-7.

84. Fortin, S.; Godbout, L.; Braun, C.M.J. Cognitive Structure of Executive Deficits in Frontally Lesioned Head Trauma Patients Performing Activities of Daily Living. Cortex 2003, 39, 273-291. [CrossRef]

85. Chevignard, M.P.; Catroppa, C.; Galvin, J.; Anderson, V. Development and Evaluation of an Ecological Task to Assess Executive Functioning Post Childhood TBI: The Children's Cooking Task. Brain Impair. 2010, 11, 125-143. [CrossRef] 